\title{
A REPRESENTAÇÃO DAS IDENTIDADES/IDENTIFICAÇÕES POR MEIO DA MODA: O FIGURINO NA TELENOVELA “CAMINHO DAS ÍNDIAS"
}

\author{
Darciele Paula Marques ${ }^{\mathrm{i}}$
}

\section{RESUMO}

Na telenovela a moda é fator determinante na construção dos personagens, pois, o figurino auxilia na caracterização dos atores discursivos e dá bases para a definição de identidades e identificações. Este estudo propõe-se a analisar os entrelaçamentos entre moda, cultura, identidade e mídia, tendo como objeto de pesquisa a telenovela "Caminho das Índias".

PALAVRAS-CHAVE: telenovela; moda; identidades; identificações

\section{RESUMEN}

En la telenovela de moda es un factor importante en la formación de los personajes, porque el vestuario de los actores ayuda a caracterizar el habla y para la definición de las identidades e identificaciones. Este estudio se propone examinar los enredos entre la moda, la cultura, identidad y medios de comunicación, a partir de la análisis de la telenovela "Caminho das Índias".

PALABRAS CLAVE: telenovela; moda; identidades; identificaciones

\begin{abstract}
In the soap opera fashion is an important factor in building character, because the costumes of the actors helps to characterize speech and for the definition of identities and identifications. This study proposes to examine the entanglements between fashion, culture, identity and media, with the object of research the soap opera "Caminho das Índias".
\end{abstract}

KEY WORDS: soap opera; fashion; identities; identifications

\section{Considerações iniciais}

A incorporação da moda, veiculada em telenovelas, pela sociedade está cada vez mais visível. É comum nas ruas pessoas falando como os personagens das tramas narrativas. Assim como, se vestindo de maneira muito similar. Desta forma, incorporam-se identidades e identificações na construção de sujeitos (múltiplos). Sem dúvida, há influência das grandes mídias neste processo, em especial da televisão, que encanta e seduz com seus recursos sonoros, imagéticos e movimento.

As grandes mídias introduzem em nossas vivências, experiências, mediadas por meios de comunicação que fazem um recorte da realidade. A moda pode exemplificar este processo, pois ela está em pauta na mídia e, por consequiência, no cotidiano das pessoas, trazendo novas tendências ou fazendo releituras. 
A incorporação da moda, transmitida pelos meios de comunicação, em especial o televisivo, é, "prontamente", incorporada pela sociedade. Com ela estão os aspectos culturais, econômicos e outros. Nas ruas, pode-se visualizar a adesão da moda midiatizada, em peças de roupas e acessórios, além da linguagem, com gírias e palavras próprias de um modismo. Observa-se que os discursos ligados à moda possuem uma forte aceitação pelo público, talvez por estar atrelado características da contemporaneidade.

A telenovela insere-se neste contexto, pois pode ser considerada um dos formatos de maior difusão de aspectos culturais identitários por meio da moda. Sua influência é tamanha que institui uma propensão a mudanças sociais, em relação a fatores/posturas que se fazem presentes na sociedade contemporânea. A proposta deste estudo reside na reflexão de sobre os entrelaçamentos que a cultura, a telenovela e a identidade realizam a partir da moda. Para tanto, utiliza-se como objeto de investigação uma seleção de capítulos da telenovela "Caminho das Índias”.

\section{Telenovela e moda}

A moda é proposta dentro da telenovela como um elemento comunicacional, transmitindo sentidos através da gama sígnica compreendida por cada elemento modal dentro da trama e ultrapassando as instâncias da ficção.

A palavra moda deriva do vocábulo fashion, que se refere à atividade e, no sentido original de sua terminologia, exprime o conceito de fetiche, tão almejado pelos consumidores que, segundo (BARNARD, 2003, p. 24), visualizam suas roupas como "hieróglifos sociais", omitindo sua posição social ao mesmo tempo em que a comunica.

\footnotetext{
A moda representa considerável relevância na sociabilidade dos sujeitos, nas interações cotidianas, atribuindo identidades e papéis sociais aos indivíduos. Os aparatos ideológicos usados pelas mídias, que articulam e difundem tendências de moda, são elementos fundamentais na percepção que os indivíduos fazem desses produtos e precisam ser investigados com propriedade a fim de esclarecer as estratégias de manipulação que elas adotam, com o intuito de defender a livre expressão identitária e o esclarecimento do indivíduo (MORAIS, 2006, p. 10).
}

O conjunto dos elementos referidos por Morais (2006) permite visualizá-la como um elo que estabelece as relações sociais, levando em consideração que este não é o único modo de constituição destas relações. A moda se faz existente a partir de duas 
concepções: a necessidade de união e a de aspiração pelo isolamento, em que se uma das duas estiver faltante, a outra não se constitui.

Estas duas acepções referem-se ao anseio do indivíduo por ser um sujeito particularizado e visto pelos demais como tal, ao mesmo tempo em que possui a necessidade de pertencimento, por exemplo, a grupos sociais, sem que corra o risco de perder sua individualidade. Neste sentido, a moda acaba por reunir estes dois fatores.

Para além destas instâncias, o campo da moda é um meio de comunicação nãoverbal, que se encontra constantemente em pauta nas mídias, que disseminam modos de vestir, agir e uma diversidade de possibilidades de criar /recriar a partir do já existente, bem como o poder de inibir os aspectos já ultrapassados.

As mídias representam papel central no processo de legitimação de gostos e referências estéticas na contemporaneidade. No campo da moda, ela própria se confunde com seu meio de articulação, tendo em vista sua dimensão espetacularizada atribuída na contemporaneidade (MORAIS, 2006, p. 10).

A experiência do indivíduo não está mais totalmente calcada nas tradições ou aspectos culturais, mas também no discurso mediado pelas instituições. Mediação que, segundo (SILVERSTONE, 2002, p.37), "é infinita, produto do desenredado textual nas palavras, nos atos e nas experiências da vida cotidiana", como exemplo pode-se citar as telenovelas, que se apropriam de fragmentos da realidade, usufruindo de maneira explícita das tendências da moda, propiciando uma incorporação significativa por parte dos espectadores. A dimensão que a mídia televisiva obtém é essencialmente relevante, ao ponto de ser um dos principais meios de propagação modal.

Deste modo, adotamos como objeto deste estudo a telenovela Caminho das Índias, que foi ao ar no dia 19 de janeiro de 2009, trazendo para a população brasileira, certas peculiaridades da cultura indiana, como vestimenta, linguagem, costumes, etc. Escrita por Glória Perez e direção de Fred Mayrink, possui uma diversidade de tendências modais que deslumbraram espectadores. Foram apresentados temas relativos à moda, cultura, culinária e costumes do povo indiano e do brasileiro.

Sabe-se que a moda possui um percurso que inicia nos primórdios da humanidade e se estende até a atualidade. Faz parte das experiências e vivências humanas, sofrendo constantes alterações, seja pelos movimentos sociais, culturais, econômicos ou midiáticos. Neste sentido, partimos da premissa de que a moda contribui 
para a criação e/ou manutenção de identidades assumidas pelos sujeitos e que, a mídia contribui de alguma forma neste processo, legitimando ou disseminando tendências.

Para efeitos desta pesquisa, considera-se a moda, a mídia e as identidades como fatores interligados, que se sustentam. Neste artigo, são apresentadas proposições que envolvem a moda, mídia e as identidades, possibilitando uma contextualização e entrelaçamentos entre estas temáticas.

\section{Entrelaçamentos entre moda e identidade}

Existem muitos conceitos de identidade, o que, muitas vezes, torna-se complexo perante aos aspectos propostos pela contemporaneidade. Isto afeta consideravelmente a questão identitária do indivíduo, chegando a formar, em alguns momentos, um simulacro da sua própria subjetividade ${ }^{\text {ii }}$. Esta situação decorre de um discurso imposto ao sujeito por inúmeros meios, numa diversidade de marcas culturais que possibilitam a desconstrução das perspectivas relacionadas à identidade pelas mais variadas áreas disciplinares, que repreendem a existência de uma identidade íntegra, nativa e única.

As identidades se fazem existentes a partir dos atributos oferecidos na linguagem e no sistema simbólico em que são representadas, sendo assinaladas principalmente pela diferença, ou seja, pela negação de algo, a fim de que seja presumido que não há possibilidade de existência de uma similaridade acerca de duas acepções, conferindo então uma disjunção entre ambas. Além de ser uma das ideações essenciais para o entendimento do procedimento de edificação cultural das identidades, percebe-se que este processo parece estar presente na telenovela, em especial a que possui na composição da sua trama, dois núcleos consideravelmente distintos, que acabam por se assemelhar as oposições binárias, pois as diferenças são apresentadas ao telespectador, tornando-se notórias. Fato que propicia ao receptor uma percepção acentuada em relação a características específicas pertencentes a determinado núcleo, principalmente quando estes aspectos estão interligados à cultura, "As identidades são fabricadas por meio da marcação da diferença. (...) A identidade, pois, não é o oposto da diferença: a identidade depende da diferença. Nas relações sociais - são estabelecidas, ao menos em parte, por meio de sistemas classificatórios" (WOODWARD, 2000, p.40).

Tanto os aspectos simbólicos, que são em meio à contemporaneidade constantemente ofertados aos indivíduos, como os aspectos sociais, que contribuem para a construção de uma identidade, são elementos que integram parte do processo identitário. Essa oferta de aspectos simbólicos e sociais é constantemente feita pela 
mídia, nos mais diferentes gêneros televisivos. Contudo, a telenovela parece acentuar ainda mais a utilização desses em consideração a outros formatos, pois o simbólico é demonstrado, principalmente, através de falas, figurinos, gestos, ou seja, aspectos facilmente identificados pela moda. Já os aspectos sociais encontram-se inseridos na narrativa construída pelos autores e posteriormente aos atores, que dão vida aos personagens, cuja personalidade e contexto remetem, em sua maioria, à atualidade, por meio de características psicológicas, culturais entre outras.

$\mathrm{Na}$ trama da telenovela analisada, a identidade nacional brasileira em relação à indiana apresentada possui diferenças gritantes, uma vez que se avalie o contexto em que estão inseridas. A identidade brasileira é marcada pela diversidade étnica e pela predominância de uma língua com uma variedade de sotaques. Já a identidade indiana é marcada pela pluralidade de religiões, a diversidade de línguas faladas, os aspectos culturais mais relacionados ao passado e, talvez, por isto mais fixos. Trata-se de uma diversidade de fatores em oposição, que formam as identidades nacionais presentes na telenovela. Identidades que não assumem mais um papel fixo, proposto pela temporalidade que se esvai. A identidade indiana mesmo parecendo "mais fechada" está em processo de reconstrução constante. Observa-se na trama que aspectos do tradicional pairaram durante grande parte do desenrolar da mesma, mas se chega ao momento em que as tradições foram perdendo forças e dando lugar a concepções novas, advindas de um ambiente mais contemporâneo.

O termo contemporâneo traz consigo a associação à mudança, que gera o surgimento de novos estilos, tendências, percepções e até mesmo convergências culturais sobre tudo que ocorre no meio social, cultural e também assuntos que perpassam estes campos. Com isso, podem-se observar alterações no processo de formação das identidades. As que se baseiam no passado/contexto histórico ou as que permanecem como afirmação para a existência de uma nova.

A representação é um aspecto importante na construção identitária, principalmente por ser parte fundamental no processo cultural. A partir da representação, que compreende um sistema de significação, é possível a exposição a um número considerável de identificações que deslocam a já existentes na identidade matriz, como ocorreu com a personagem Dayse (Betty Gofman), pois diante de uma variedade representacional ela demonstra uma identificação muito forte com aspectos da cultura indiana e começa aderir a esta de uma forma desconcertante. A representação 
(...) inclui as práticas de significação e os sistemas simbólicos por meio dos quais os significados são produzidos, posicionando-nos como sujeitos. É por meio dos significados produzidos pelas representações que damos sentido à nossa experiência e àquilo que somos. Podemos inclusive sugerir que esses sistemas simbólicos tornam possível aquilo que somos e aquilo que podemos nos tornar. A representação, compreendida como processo cultural, estabelece identidades individuais e coletivas (...). (WOODWARD, 2000, p.17)

A moda é um dos assuntos abordados continuamente pela mídia. Ela transita livremente pelos diversos programas de televisão, o que há faz estar em pauta nas conversas cotidianas. Segundo (CASTILHO, 2005, p. 20), a moda, “em todas as suas maneiras ou formas diferenciadas de manifestação, um traço específico que não se altera: o da diferenciação e distinção do sujeito e o da construção de sua identidade". Pode-se dizer desta forma, que a moda possui a questão representacional muito aguçada, ligadas aos aspectos simbólicos e significativos que atuam no processo de formação das identidades, por compreender fatores de diferenciação e similaridade ao mesmo tempo.

No sistema de representação são compreendidas a produção de significados e a produção de identidades que estão estreitamente correlacionadas. A representação engloba uma gama de significações, que por sua vez encontra-se carregada de poder e acaba por dar vazão às escolhas, vide o exemplo da personagem Dayse. Para Woodward (2000, p.33) "Toda a prática social é simbolicamente marcada. As identidades são diversas e cambiantes, tanto nos contextos sociais nos quais elas são vividas quanto nos sistemas simbólicos por meio dos quais damos sentido a nossas próprias posições".

A percepção sobre o conceito de identificação foi um dos menos aperfeiçoados da conjectura social e cultural, não propiciando respaldo sobre os enigmas que passam a existir a volta do conceito de identidade. No senso comum, "a identificação é construída a partir do reconhecimento de alguma origem comum, ou de características que são partilhadas com outros grupos ou pessoas, ou ainda a partir de um mesmo ideal”, já na interpelação discursiva a identificação é vista "como uma construção, como um processo nunca completado - como algo sempre em processo" (HALL, 2000, p. 106). Acredita-se que a identificação é um procedimento de junção e não de fragmentação.

A assimilação permite primeiramente, um afeiçoar em relação ao outro, reforçando ainda mais a diferença que consente a formação da identidade. Um dos fatores que tem causado perturbações em relação ao estabelecimento de um conceito fixo de identidade são os aspectos da contemporaneidade. Sendo que, isso requer um 
retorno originário do passado, definindo "o sujeito ao qual nos tornamos", "o que podemos ser" e "como temos sido representados" e não necessariamente "o que somos". Estas questões são tão correlacionadas com a concepção da tradição quanto ela própria.

$\mathrm{Na}$ telenovela todos os personagens correspondem a eu's discursivos, pois “surge da narrativização do eu” (HALL, 2000, p.109). São criados a fim de representar comportamentos e atitudes diante de determinadas circunstâncias dentro da trama narrativa. $\mathrm{O}$ que possibilita afirmar que há a existência de um processo de construção de uma identidade discursiva, amparada em códigos sociais, culturais, históricos e outros, que é efetuado a partir de releituras do real, porém em um discurso construído através de percepções midiáticas.

A necessidade de entendimento da identidade está compreendida no discurso, pelo fato da mesma ser edificada no interior desta preleção, de constituição e usos específicos a partir de táticas e empreendimentos particulares. Do mesmo modo, que passam a existir no cerne do jogo (das identidades), formas exclusivas de poder, mais uma vez afirmando a instância da diferença e efetuando a exclusão "do que o signo de uma unidade idêntica, naturalmente constituída, de uma 'identidade' em seu significado tradicional - isto é, uma mesmidade que tudo inclui, uma identidade sem costuras, inteiriça, sem diferenciação interna" (HALL, 2000, p. 109).

As identidades são representações que somos (nós sujeitos) compelidos a ostentar um lugar de fala e obter este direito de fala, mesmo sabendo que as representações, como menciona o autor, são erigidas a partir do lugar assumido pelo outro, por isto nunca podem ser convencionadas. Logo, se as identidades são representações, pode-se dizer que a moda é um processo intenso de representação que desencadeia identificações e projeta identidades, que reúnem aspectos históricos, culturais e outros, segundo (HALL, 2000, p. 112), "Isso, por sua vez, coloca, com toda a força, a identificação, se não as identidades, na pauta teórica”. Na telenovela e no campo da moda trata-se de um processo múltiplo, representado através de personagens variados que se constituem por meio da linguagem, vestuários e outros.

Deste modo, o conceito de identificação parece estar mais presente nas tramas narrativas midiáticas, uma vez que a contemporaneidade propicia esta volatibilidade de interações para com os personagens e seus conteúdos, principalmente em relação à telenovela que se projeta para o real em uma mão dupla de significações. A cada telenovela, são apresentadas novas possíveis identificações, assim como, ocorre com as tendências da moda representada nos figurinos dos personagens e fala, que são 
facilmente assimilados pelos telespectadores, ou seja, um processo constante de reconstituição ou reposição.

É presente, deste modo, a influência de pensamentos da pós-modernidade, que trazem consigo tendências, como é o caso da internacionalização, inserindo nas vivências fragmentos de outra cultura, geralmente americanizada. No meio televisivo isto é comum, seja por meio de palavras, imagens ou costumes, que não faz(ia)m parte do contexto social daquele dado momento. Estes elementos são rapidamente assimilados por parte dos leitores dos programas televisuais e passam a pertencer a sua cotidianidade, como por exemplo, palavras em hindu, movimentos expressões também da cultura indiana.

Adotam-se novas identidades rapidamente, seja para desenvolver o sentimento de pertencimento ou por auto-afirmação daquilo que você não é em sua maioria e aquilo que julga ser. Pode-se observar que a identidade está, especificamente, ligada ao consumo de uma forma linear, pois no instante que se assume uma identidade, significa que há consumo de um discurso.

\section{Aspectos modais representados por meio dos figurinos}

$\mathrm{Na}$ telenovela há um jogo ininterrupto marcado pela efemeridade da moda, que pode ser percebido pelo figurino utilizado na trama narrativa, reforçando elementos próprios da estética contemporânea. A moda representa através dos figurinos dos personagens elos com a contemporaneidade, que contribuem com a formação das identificações ou identidades.

A presença da moda na caracterização dos personagens e nos figurinos também possibilita uma mediação com o cotidiano dos telespectadores, principalmente em telenovelas que mesclam o tradicional e o contemporâneo. De certa forma, acabam por retratar um mundo em constante movimento evolutivo. Neste sentido, a telenovela atua como um fator de aproximação das identidades e identificações propostas com a contribuição da moda no estilo de vida dos espectadores. Porém, a moda só vem fazer parte da telenovela a partir de um link com o figurino.

No início da utilização da moda na telenovela, nos anos 1970, sua expressão maior estava nos acessórios, ao contrário do que ocorre atualmente quando a moda está presente não somente no figurino como também, nos cenários e nas falas, possibilitando uma aproximação do telespectador com os diálogos da moda apresentados através da sua narrativa. 
A telenovela se tornou a uma grande vitrine modal, a partir dos elementos como fala, figurino e expressões dos personagens. Deste modo, se faz viável avaliar os figurinos de alguns dos personagens para analisar que tendências são propagadas e se há implícito algum processo legitimador de identidades e identificações a partir da moda.

A trama da telenovela em questão possui a fragmentação de sua narrativa em dois núcleos que apresentam contrastes muito acentuados, que acabam por se refletir também nos figurinos dos personagens dos diferentes núcleos. A seguir apresentam-se algumas descrições de figurinos dos personagens que mais se destacaram ou que instigaram processos de identificação, descrevendo de forma geral suas roupas e uma breve análise conjectural.

A personagem Maya quando ainda não estava de compromisso marcado com Raj usava punjabi (conjunto composto por uma túnica e uma calça mais justa, traje tipicamente feminino), porém depois do casamento faz uso dos sáris, que são geralmente das cores vermelha, rosa pink, salmão, entre outros, compostos por fios dourados e de forma desalinhada a presença de paetês também na cor dourada. Na borda que envolve a cabeça há uma linha mais espessa de bordados dourados. Seu Bindi é formado por uma seqüência de pequenos círculos pretos na posição vertical e uma tikka, presa ao seu cabelo que se assemelha ao formato de uma concha composta por algumas pedras coloridas, sendo que no centro há uma pedra maior na cor branca. Seus brincos se assemelham ao formato de uma folha em prata que se estende até atrás da orelha, assim como o seu tikka, com várias pedras coloridas. Em seu pescoço encontra-se apenas o seu Mangal Sutra.

Em seu Choli (blusa curta usada em baixo do sari), os bordados em dourado são muito acentuados na gola e no centro do peito, por serem mais espessos e ricos em detalhes. No seu pulso esquerdo e direito há muitas pulseiras em diversas cores desde ouro, prata, entre outros. Usa sombra rosada com olhos bem delineados pelo Kajal. Seus cabelos são presos e em sua mão esquerda e direita, mais especificamente no dedo indicador, usa um anel de forma oval. Suas unhas estão pintadas na cor rosa bebê e sua bolsa é de cor caramelo.

Pelo modo como a personagem se veste é possível afirmar que Maya é uma típica indiana de sua classe, que dissemina os aspectos culturais a partir de seu figurino e outros elementos concernentes a estes. Reflete a posição da mulher na Índia, que deve estar sempre muito bem arrumada para o seu marido, figura 1, com muitos acessórios, 
além de cuidar bem de sua família e "ser" esteticamente bela, reflete um modo de pensar, um sentimento do culto à beleza e aos costumes.

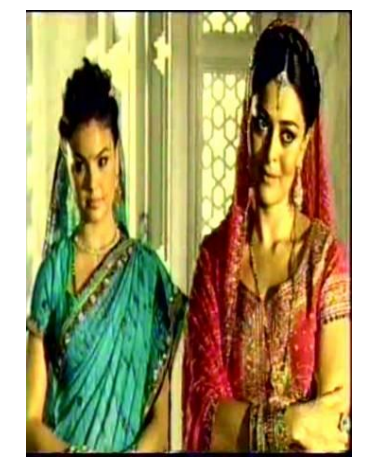

Figura 1: Personagens Maya

Fonte: retirada da gravação da telenovela Caminho das Índias

Inês, figura 2, mescla gótico, punk e rock. Ela faz um paralelo entre o nostálgico e o romântico em seu figurino. Faz uso de acessórios que podem ser incluídos normalmente no visual cotidiano sem causar muito estranhamento, como os colares, por exemplo. Dona de um visual muito marcado pela criatividade deixou claro o dia em que a mesma usava uma camiseta com leds na estampa. Outro figurino da personagem é o de cabelos soltos, camiseta preta com um babado branco e uma fita preta em forma de laço, com um colete jeans, um short jeans desfiado na extremidade, uma meia calça rasgada, uma bota cano baixo preto, com um meião branco e batom marrom.

O estilo adotado retrata uma tendência que já se propaga pelo cotidiano, mas para um olhar desavisado pode remeter à imagem de garota de classe alta alienada, que perde credibilidade pelo fato de possuir um estilo diferente do habitual.

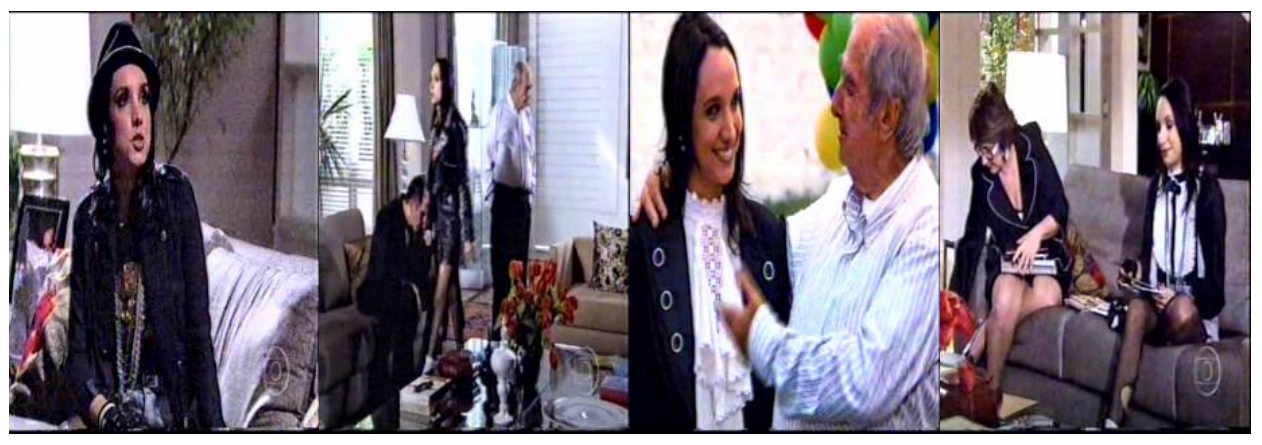

Figura 2: Personagem Inês

Fonte: retirada da gravação da telenovela Caminho das Índias

A personagem do núcleo brasileiro, Dayse não poderia deixar de compor esta seção, pois ressalta pelo contraponto com o figurino dos demais personagens. Ela esbanja cores, além de fazer uma ligação dos dois países da trama narrativa. 
A personagem vai para a Índia e fica deslumbrada com o que vê no oriente e começa a comprar tudo que acha bonito, sem ao menos saber o significado das peças, principalmente em relação ao sistema de castas. Deste modo, a personagem Dayse usa veste uma calça saruel, figura 3, acompanhada de pulseiras douradas em ambos os pulsos. Um colar de bolinhas pretas e douradas e o pingente - uma pedra transparente quadrada. Sua bolsa é pequena e disposta transversalmente. Usa batom vermelho escuro e anel no dedo médio da mão direita, sendo que seu brinco remete à flor de lótus.

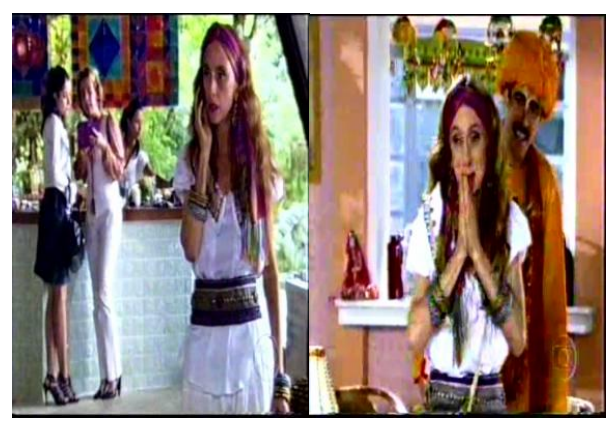

Figura 3: Personagem Dayse

Fonte: retirada da gravação da telenovela Caminho das Índias

Pode-se afirmar que a personagem possui um estilo folk que denota uma cultura diferente e dentro deste figurino estão representadas todas as castas. Dayse faz um mix de elementos que se identificou e acredita ter encontrado sua verdadeira identidade.

Pode-se perceber que a moda auxilia o sujeito a se expressar ou demonstrar aquilo que ele quer ser. Como os indianos, pelo menos os exibidos na telenovela analisada, que refletem em suas roupas a sua essência, uma forma de representação, que também atua como sistema se aproximando e se afastamento de determinados grupos. A roupa comunica, ela é carregada de significação, propondo identificações. A telenovela difunde e cria moda, através dos figurinos e outros. Neste sentido, as telenovelas propiciam espaço para a disseminação de estilos e tendências modais a partir de diversas representações, bem como a mesma cria essas.

Os figurinos não ditam apenas formas de vestir-se, mas comportamentos, modos de pensar e outros, como por exemplo, o figurino utilizado pelo núcleo indiano representa mais do que apenas um modus de vestir-se, mas corresponde a um código implícito de aspectos culturais, tradicionais e religiosos.

Os personagens vestem-se com mais que apenas roupas, que ditam um estilo ou uma influência modal. Os personagens vestem-se com atributos de significação que não se delimitam ao espaço e ao tempo, como o caso dos saris usados pelas personagens. Os 
figurinos como o de Inês e Leinha correspondem a uma sobreposição de trajes, que em um momento possuem o ápice das incorporações, mas não conseguem alcançar o nível de significação de uma "indumentária", no sentido barthesiano, mesmo que não seja aquela tradicional.

É importante ressaltar que quando se fala em moda nesta subseção refere-se à utilização da mesma para a composição do figurino do personagem, obedecendo desta forma regras do estilo e da personalidade criada para cada um. Não é a moda que dita como os personagens se vestem, é por meio dela que são legitimadas as identidades e as identificações destes, sendo a moda um instrumento, fator de mediação.

\section{Considerações finais}

Em uma telenovela com contrastes sociais e culturais tão acentuados, a moda tem papel fundamental na construção destas identidades, bem como também das identificações, pois a trama narrativa buscou mostrar o lado oriental, rico pela sua significação e simbolismo. A moda foi representada aqui por meio do figurino de alguns personagens, mas sabe-se que o vestuário não é o único meio disseminador de aspectos modais, pois a moda em sua totalidade compreende outras formas de representação em meio à contemporaneidade. No entanto, como forma de delimitação de análise, este estudo primou pelo figurino.

A moda marca a representação das identidades dentro da telenovela, através do figurino, como uma das representações que se apresenta com maior ênfase, pois se faz um resgate de elementos essenciais para o desenrolar da trama, atuando como textos. Nesta telenovela o figurino é uma agente comunicador que opera a partir da representação.

As identidades são marcadas pelos contrastes dentro da trama da telenovela. Trata-se de uma representação dentro de um meio midiático, o que pede releituras para a inserção neste meio, que se apropriam da realidade, mantendo de maneira mais fiel possível a essência das mesmas, mas isso não impede adaptações, que concebem então as identidades culturais midiatizadas e mediadas pelo meio.

No caso brasileiro, a legitimação da identidade cultural se dá a partir da moda, diferentemente da indiana, a do Brasil sofre muitas influências estrangeiras, propiciando assim um maior número de identificações, pelas variações de tendências e estilos presentes neste âmbito, como por exemplo, a Leinha que tem um estilo Hippie Chic que reúne vários elementos contemporâneos, com o modo de expressão de um movimento 
que marcou o Brasil e o mundo nos 1970, buscando enfatizar o amor livre e a nãoviolência, reconstruindo então o estilo passado com aspectos do presente como jovialidade e até mesmo a elegância. A personagem Inês que mescla vários movimentos como punk, que se tornou a representação de uma tribo urbana, o rock que é um gênero musical com variações dentro do mesmo e com o estilo gótico que é caracterizado como um fase da história da arte ocidental ligado aos contextos social, político e religioso. Esta fusão de estilo, movimento e gênero deu origem a um estilo modal Dark Romance, também a partir de uma reconstrução de elementos. A personagem Dayse com seu estilo folk, originário da Índia, deslumbrada pela profusão estética e aspectos culturais faz um junção de elementos de várias castas.

Todo o contexto exposto permite afirmar que há uma multiplicidade de identificações proposta dentro da trama da telenovela, principalmente no núcleo brasileiro, que é mais flexível em relação a essas apropriações. No núcleo indiano, o figurino foi um fator fundamentalmente contributivo para a disseminação da identidade cultural (midiatizada), pois ali se fundamenta a representação de muitos elementos impregnados nas roupas, principalmente quando se refere à mulher, considerada fonte de vida e demonstrada pela diversidade de cores em seu figurino.

Deste modo, a moda contribui para legitimar as identidades e propor identificações pela sua facilidade de adaptação ao meio. Todos estes aspectos são compreendidos dentro do contexto atual, em que a efemeridade é algo presente, assim como o hibridismo, que perpassam o campo identitário e o modal. Por fim, cabe destacar que o conjunto destes atributos é estrategicamente selecionado por critérios representacionais-identitários que unificam, ao mesmo tempo em que diferenciam.

\section{Referências}

BARNARD, M. Moda e comunicação. Rio de Janeiro: Rocco, 2003.

BARTHES, Roland. Imagem e moda. São Paulo: Martins Fontes, 2005.

Elementos da semiologia. São Paulo: Cutrix, 2006.

CASTILHO, Kathia. Discursos da moda: semiótica, design e corpo. 2. ed. São Paulo: Anhembi Morumbi, 2005.

HALL, Stuart. Quem precisa de identidade? In: SILVA, Tomaz Tadeu da. (org.) Identidade e diferença: a perspectiva dos estudos culturais. RJ: Vozes, 2000. 
MORAIS, Michael Medeiros de. Moda e mídia: aspectos culturais, identitários e sociais. In: Intercom - XXIX Congresso Brasileiro de Ciências da Comunicação, Brasília, 2006.

SILVERSTONE, Roger. Porque estudar mídia? São Paulo: Loyola, 2002.

WOODWARD, Kathryn. Identidade e diferença: uma introdução teórica e conceitual. In: SILVA, Tomaz Tadeu da. (org.) Identidade e diferença: a perspectiva dos estudos culturais. RJ: Vozes, 2000.

\section{Notas}

i Mestranda do Programa de Pós-Graduação Stricto Sensu em Ciências da Comunicação pela Universidade Federal de Santa Maria. Graduada em Comunicação Social -. Publicidade e Propaganda pela Universidade Federal do Pampa. E-mail: darciele.marques@ hotmail.com

ii Faz-se existente uma superposição entre os termos "identidade" e "subjetividade", porém o segundo "termo envolve os pensamentos e as emoções conscientes e inconscientes que constituem nossas concepções sobre quem nós somos. A subjetividade envolve nossos sentimentos e pensamentos mais pessoas. Entretanto, nós vivemos nossa subjetividade em um contexto social no qual a linguagem e a cultura dão significado à experiência que temos de nós mesmos e no qual nós adotamos uma identidade. (...) $\mathrm{O}$ conceito de subjetividade permite uma exploração dos sentimentos que estão envolvidos no processo de produção da identidade e do investimento pessoal que fazemos em posições especificas da identidade. Ele nos permite explicar as razões pelas quais nós nos apegamos a identidades particulares" (WOODWARD, 2000, p.55-56) 